\title{
Sedimentando a teoria da cidade do Sul no tempo e lugar*
}

Alan Mabin**

Resumo: Ao mesmo tempo que simpático ao projeto de uma teoria urbana do Sul global e suas pretensões, este artigo é cético sobre a utilidade de uma "teoria urbana desde o Sul". O que precisamos, ou não temos ainda, é algo que não pode ser atingido somente desde o Sul, já que o mundo não está dividido de forma tão simples. O artigo rejeita a noção de que as teorias do "Norte" não possam ser úteis no Sul. Sugere que, ao invés disso, as teorias viajam e, ao fazer isso, são enriquecidas em lugares, regiões, redes e em conversações. Trabalhando entre Paris, Johanesburgo e São Paulo, o artigo sugere uma formulação relacional levando em conta os terrenos comuns entre o Norte e o Sul.

Palavras-chave: teorias do Sul, cidades do Sul, conexões, relações, urbanismo.

\author{
* Palestra proferida \\ no Programa de \\ Pós-Graduação em \\ Sociologia/UnB. \\ Revisão técnica de \\ Marcelo C. Rosa. \\ ** Professor de \\ estudos urbanos, \\ Universidade de \\ Pretória, África \\ do Sul.<alan@ \\ alanmabin.org>
}

\section{Introdução}

s cidades são sempre incompletas e estão sempre em transição. Pode-
ria um mesmo conjunto de ideias e conceitos ajudar a compreender
o que está acontecendo em todas as cidades? São as cidades completamente singulares, ou há distintos grupos de cidades, para os quais modos específicos de pensar se aplicam? Assim como a maioria das perguntas teóricas, a possibilidade de generalização dessas declarações sobre as cidades inevitavelmente surge neste contexto. Ao conduzir um trabalho detalhado sobre alguns eixos comparativos selecionados em São Paulo, Paris e Johanesburgo, defrontei-me com a possibilidade da comparação entre cidades localizadas em cenários aparentemente bem distintos. É através destas rotas que inserções contemporâneas da "teoria do Sul" no debate se tornam significantes para o meu trabalho. Ao pesquisar e escrever sobre a mudança em três continentes, uma única teoria de cidades, ou como Rao (2006) sugere, uma estrutura universal fracassa em explicar meus lugares de pesquisa. Nessa situação, a "teoria do Sul" (Connell, 2007) cruzou meu caminho tanto para pensar as cidades do Sul, como as do Norte. Na mesma senda, estudantes de antropologia urbana, arquitetura, geografia, história, planejamento, política e sociologia estão hoje imersos na ideia de que cidades do Sul não possam ser entendidas pela teoria do Norte ou ocidental, e clamam por novidades.

Neste contexto, consideramos a seguinte questão: o que é a "teoria do Sul", ou ainda, o que é a "teoria urbana para além do Ocidente" (Comaroff \& Comaroff, 2011; Edensor \& Jayne, 2012)? 
Devemos ter cautela com o problema do uso de modelos - de Chicago a Los Angeles, passando por Miami, Atlanta e outros exemplos. Além disso, a noção de "Sul" ou de "cidades do Sul" evoca, em geral, uma mudança pós-colonial em muitas disciplinas, e sua possível intersecção com críticas da economia política (da "teoria de dependência" ao "antineoliberalismo"). Uma proposta crucial na atual discussão é que as "cidades do Sul" apresentam um espaço de experimentação que prefiguram o futuro próximo do Ocidente (ou do Norte). No entanto, o risco de adoção generalizada de tais perspectivas pode ser "um conjunto ainda maior de afirmações que tendem mais obscurecer do que esclarecer" (Aravamudan, 2012).

Consciente da possível rejeição dessa teoria, interpretando-a como mais uma "ansiedade obsessiva sobre as últimas modas da teoria do Norte" (Mbembe, 2011; 2012), exploro o que pode se ganhar considerando, para o mundo de cidades, as novas realidades e as novas concepções que emergem "do Sul". Para Roy e Ong (2011), "tanto a economia política como as estruturas pós-coloniais" são limitadas. Eles afirmam que nenhuma delas é "suficiente para capacitar teorizações robustas do espaço-problema presentes na cidade contemporânea". Nesse sentido, deve haver uma busca por "novas abordagens nos estudos metropolitanos globais", que estejam para além da simples classificação das cidades na esfera de um roteiro singular, do "capitalismo planetário", ou que busque "'resistências subalternas' em cidades que uma vez foram submetidas ao domínio colonial” (Roy, 2011: 307).

O artigo reflete sobre o que é a teoria do Sul, considerando, com algum ceticismo, as seguintes questões: O que queremos dizer com "cidades do Sul" e com a teoria "nelas" ou "delas"? Há algo mais geral a apreender desde as cidades do Sul? Quais são os limites das concepções de "teoria urbana do Sul" ou "pós-ocidental"? E, finalmente, adianta algumas das consequências de se colocar em ação as teorias do Sul para pensarmos políticas, programas, planejamentos, práticas, democracia, assim como para as várias possibilidades de se escrever sobre a cidade.

\section{O que é a "teoria do Sul"?}

De onde se origina o uso do termo "Sul"? Aravamudan (2012) sugere que a origem está no relatório "Norte-Sul", de Willy Brandt, que

tentou transpor a principal divisão de desenvolvimento do mundo dos anos 1970, do impasse representado pela Guerra Fria que foi vista como uma divisão "Oriente-Ocidente". Ocasionalmente, meramente "Sul" e supostamente de maneira educada se substitui por "o que chamávamos de Terceiro Mundo" (Comaroff \& Comaroff). Da mesma forma que [Comaroff \& Comaroff] reconhecem que o "Sul", de maneira ampla, significa "pós-colonial" (Aravamudan, 2012). 
Certamente podemos usar essa noção para incluir o mundo pós-colonial inteiro, bem como os espaços citadinos de Londres a Brisbane (ver, por exemplo, Jacobs, 1996). Não há precisão nesses termos e esta não parece ser a intenção daqueles que debatem o tema. Há de fato um problema se entendermos, por exemplo, o "Sul" como categoria geográfica, ou cidades do Sul como tal, porque assim impomos ideias espaciais sobre uma categoria relacional: o "Sul" se refere às relações sociais, e não a um lugar. Grovogui (2011: 175) lembra-nos que o termo se refere a um movimento visível de formas contraditórias, a partir da conferência de Bandung, em 1955. Ao cabo, a oposição binária que o termo "Sul" evoca parece ser "Ocidente" versus "Sul", como na frase do título da coletânea de Edensor e Jayne (2012) chamada "pós-ocidentalismo".

Neste texto, uso o termo "Sul", de forma ainda pouco precisa, menos como expressão geográfica (embora seja inevitável, e persista uma tensão geográfica/conceitual), e mais para me referir a uma situação dual da pós-colonialidade e de economia política particular. Em geral, oponho à noção de Sul as noções de Norte e, às vezes, de Ocidente, como sugerem muitos exemplos da literatura: às vezes usando outros termos ("Sul-Oriente" ao invés de "Sul", por exemplo, em Yiftachel (2006), e em Watson (2013), embora essa seja uma referência geográfica que pode não repercutir na América do Sul).

A primeira característica do termo "Sul" presente nessa literatura corrente é de estar, pelo menos anteriormente, muito sob a hegemonia de pessoas e organizações e concepções de um "outro lugar" e de uma "cultura diferente". Um componente do "Sul" é, indubitavelmente, a colonialidade/pós-colonialidade. Não se pode dizer aqui que o colonialismo "não exista mais", porque muitos acadêmicos - a começar por Bhabha (1994) - argumentam que as culturas coloniais continuamente interferem no presente. Mas há um segundo componente: o Sul global remete aqui particularmente às condições de escassez às maiorias - quaisquer que forem os níveis de abundância para as minorias. Tal imagem faz parecer que problemas negativos se definem por meio da "falta" ou da ausência, mas a companhia da escassez é um complexo de criatividade, engenhosidade e experimentação, que é capturada na noção da provisão nos relacionamentos e interações de pessoas na parte Sul do mundo. O Sul e as cidades do Sul são marcados por uma economia política de recursos insuficientes necessários para uma vida decente a todos. É nessas intersecções que se tenta promover e engajar a "teoria do Sul".

Conceitualmente, a "teoria do Sul" é o terreno das intervenções de duas das contribuições recentes mais citadas que a aprofundam - as da socióloga australiana R. Connell (2007), e dos antropólogos Comaroff e Comaroff (2011). Até certo ponto, estes autores baseiam suas obras em outras, de acadêmicos associados às ideias do Sul, tais como Aijaz Ahmad, Arjun Appadurai, Homi Bhabha e Dipesh Chakra- 
barty; Gayatri, Chakravorty e Spivak, especialmente Spivak (1999). Além desses, há outros cujos trabalhos foram lidos como obras do pós-colonialismo - com destaque para Fedric Jameson, Achille Mbembe, Ngugi Wa Thiong'o - em obras escritas, em grande parte, em inglês e, ocasionalmente, em francês, como Guénif-Souilamas (2012); e ainda Obarrio (2012b), Moraña et alii (2008), refletindo, de alguma maneira, uma série diferente de literatura da América Latina, escrita originalmente em português e em espanhol.

As "teorias do Sul" emanam da ideia geral de que "o Sul" pode produzir diferentes perspectivas, conceitos, argumentos em relação aos tradicionais entendimentos profundamente imersos na experiência do Norte ou do Ocidente. Mas, além da ideia, ou afirmação, qual é o problema que está sendo exposto? Em outras palavras, o que exatamente a teoria "do Norte ou do Ocidente" não consegue incluir?

Um tema central é que ideias usadas em grande parte das descrições e teorias sociais originam-se no Norte, e que as ideias provenientes do Sul são, boa parte do tempo, ignoradas nestes relatos hegemônicos.

Assim como muitas obras pós-coloniais, Connell (2007) tenta estabelecer "qual visão de mundo e de seus habitantes está em vigor" na teoria social. O autor argumenta contra as afirmações da universalidade pretendidas por Bourdieu, Giddens e Coleman e sustenta que estes teóricos sociais fracassam ao incluírem as particularidades do Sul.

Autores como Connell (2007) ou Comaroff e Comaroff (2011) não cobrem uniformemente todo o espectro do "Sul", nem afirmam cobri-lo. Em particular, evitam incluir a América Latina entre as descrições e as proposições aplicadas em grande parte da Ásia e da África. Salvatore (2010), de maneira convincente, argumenta que

a literatura latino-americana e os estudos culturais têm praticado a crítica do impacto do colonialismo na cultura e têm criticado o eurocentrismo muito antes que Said, Spivak ou Bhabha aparecessem na paisagem intelectual das universidades do norte do Atlântico (Salvatore, 2010: 333-334).

Entretanto, o propósito da "teoria do Sul" - assim como toda a teoria social - está no terreno do poder. Uma intenção profunda da "teoria do Sul" é a desestabilização do pensamento do Norte - e daqueles que o elaboram. Isso não é fortuito, coincide e intersecta com outras mudanças geracionais. No caso da obra pós-colonial e de sua parcial descendência, a "teoria urbana do Sul" tem sua motivação nos caminhos penetrados por Chakrabaraty (2000) e (Mbembe, 2010; 2012), o provincialismo do mundo do Atlântico Norte e do mundo do Sul. 
Ao deixar de lado todos os tipos de dificuldades de classificação que definem este artigo, a teoria do Sul tem várias linhas de argumento. Eu reflito sobre quatro delas nesta exposição:

1. que a teoria do Norte fracassa e não se aplica ao Sul;

2. que o futuro está delineado no Sul, não no Norte;

3. que o eixo de poder Norte-Sul pode ser invertido - que hegemonias do Norte podem ser intelectualmente desafiadas - que a Europa pode ser provincializada (Chakrabarty), e a África pode ser mundializada (Mbembe); e

4. que eventos e ideias do Sul são importantes para se entender o mundo como um todo e não somente o Sul.

A subsequente discussão neste capítulo inclui estas linhas de argumento em relação às "cidades do Sul".

\section{"Cidades do Sul"}

e a teoria para "elas", "nelas" e "delas"

Ao seguir as linhas gerais da "teoria do Sul", uma tendência afirma que a teoria urbana "do Norte" ou "do Ocidente" não consegue lidar com a explicação das cidades no "Sul global" (Edensor \& Jayne, 2012; Watson, 2009). Há algum consenso sobre o fato da necessidade de um novo tipo de urbanismo para refletir a realidade das cidades no século XXI (ver Parnell, 2012; Roy, 2009, entre outros) e, dentro desta perspectiva, talvez de um "urbanismo comparativo pós-colonial" (ver McFarlane, 2010; Robinson, 2011a; 2011b). Ao expressar este sentimento de forma direta, a publicação International Journal of Urban and Regional Research publicou a seguinte chamada de artigos:

Para desafiar teorias derivadas do Norte global... cidades através do Sul global podem trazer desafios fundamentais às teorias do Norte global. Ansiamos por um tempo em que a nossa teoria urbana emane de estudos produzidos em Buenos Aires... assim como de estudos realizados em Chicago ou em Los Angeles (Seekings, 2012).

Assim, no âmbito dessa controvérsia, uma sucessão de noções povoa obras sobre possíveis diferenças entre a teoria urbana do "Norte" ou "do Ocidente" e o que está acontecendo nas cidades do Sul.

Um caso central diz respeito ao emprego da palavra "moderno". A noção de uma exportação da modernidade ou do modernismo das cidades do Norte para as cida- 
des do Sul tem sido contestada há muito tempo em discussões sobre hibridismo, multiplicidade, provincialização, subalternidade e experimentação, como mostra Leontidou (1996). Tal crítica sugere que "a metrópole ocidental [seja] implicitamente considerada como mais desenvolvida, complexa, dinâmica e madura" do que a "não ocidental" (Robinson, 2003, apud Edensor \& Jayne 2012: 3). A consequência é uma teoria urbana baseada na linearidade: o que ocorreu nas cidades do Norte, no século XIX e início do século XX, seria reproduzido nas cidades do Sul. Sob ataque, juntamente com a teoria da modernização e suas variantes, tais argumentos ainda estão presentes em muitos dos escritos urbanos - compartilhados em manuais acadêmicos bastante sofisticados sobre cidades, a maioria deles escritos e publicados no "Norte", nos quais a maior parte das páginas é absorvida por ilustrações do Norte sobre as "cidades do Sul", adicionadas simplesmente para serem analisadas e entendidas através das noções (do Norte) estabelecidas nas páginas anteriores.

A passagem empírica da maioria da população da cidade global para o Sul tem, certamente, feito refletir muitos dos que procuram contemplar cidades de todo o mundo como um bloco. É, em parte, esta nova realidade que traz ansiedade e entusiasmo, levando leitores a produzirem novos textos sobre o tema. Ordinary cities de Robinson (2006), é um exemplo bastante proeminente. Deste conjunto de obras, emerge a hipótese alternativa de que cidades do Sul revelam algo novo.

Mesmo sem ir ao extremo da afirmação sobre a existência de uma nova linearidade, o futuro do Norte - ou do Ocidente - é agora visível em cidades do Sul. Esta é uma hipótese poderosa e atraente. No entanto, podem ocorrer tensões entre a perspectiva de que as cidades são parte de um todo homogêneo, e a concepção que defende não ser satisfatória a teoria do Norte. Em comum há o fato de que é inaceitável que cidades do Norte sejam academicamente privilegiadas, e que as cidades do Sul sejam negligenciadas e evitadas.

A questão aqui é mais profunda do que simplesmente constatar que as cidades ocidentais são objeto de extensa literatura, de pesquisas e debates, enquanto "as demais cidades do mundo permanecem relativamente mal compreendidas" - um ponto importante da crítica de Choplin (2012) a diversos trabalhos, incluindo o de Edensor e Jayne (2012).

Uma faceta da "teoria urbana do Sul" poderia ser seu conhecimento mais profundo das cidades do Sul. Em 2010, Simone evocou o que poderia ser considerado novo e diferente nas cidades do Sul por meio da noção de "movimentos na encruzilhada". Seu constructo apresenta virtudes que repercutem junto a muitos leitores. Houve grande repercussão do trabalho, até mesmo para além dos interessados nas cidades do Sul, mostrando que as coisas menos visíveis no âmbito urbano são a chave para 
novas questões sobre a cidade em geral. Por exemplo, sobre o governável e o não governável, sobre como as coisas são e como não são governadas na cidade (Le Gales \& Vitale, 2013).

O que é novo e diferente? O que tem sido omitido pelos conceitos mais antigos do Norte? Em uma escala muito menor do dia a dia, da rua, da casa, do grupo aparentemente casual, como os cidadãos periféricos criam e recriam "uma nova socialização urbana, mesmo sob condições terríveis", através de vários experimentos e possibilidades para a cultura popular (Simone, 2010: 314-316). “A cidade é uma maneira de manter coisas abertas e de materializar caminhos, de tornar algo que não existiu antes viável" (Simone, 2008: 201). A obra de Simone, não obstante seus limites (ver abaixo), motivou um grande número de leitores a pensar na cidade em termos de seu caráter provisório, da circulação, das operações, das intersecções e da intermediação.

Sem parar por aqui, os rumos desse debate se multiplicam: em direção ao esquecimento do peso da farta literatura sobre as "cidades do Norte", ou, mais radicalmente, afirmando que cidades do Norte podem ser mais bem entendidas através de concepções das cidades do Sul, já que aí o "novo" é encontrado. A estrela global da atual onda da teoria da cidade do Sul, Roy (2009) apela por "novas geografias" da imaginação e da epistemologia na produção da teoria regional e urbana. Ela procurou explorar a produção do espaço em certas cidades do Sul, de Calcutá a Beirute. Juntamente com Simone, ela descreve a "mundialização" da cidade enquanto processos múltiplos e diversos, envolvendo o domínio de técnicas contemporâneas de governança para além das elites, e assim operacionalizar formas de "tornar mundial" desde baixo, de reformular a representação da cidade (Roy, 2011).

A fim de ir para além da oposição vertical de "cima" e de "baixo", Simone apela por uma abordagem "latitudinal". Ideias e conceitos similares podem ser encontrados em recentes coletâneas que popularizam ilustrações em cidades do "Sul". Ao questionar modernidades no centro de sua abordagem, Edensor e Jayne (2012), por exemplo, estruturam sua coletânea sobre "teoria urbana além do Ocidente" com títulos tais como "descentralizar a cidade", "ordem/desordem", "mobilidades e imaginários", "tropos de improvisação conhecidos", "multiplicação de oportunidade" e acesso ao maior número de redes possível. Desta coletânea, são extraídas as bases para a proposição de Simone, em sua própria contribuição ao volume, de que as cidades do Sul "não são mais subalternas" (Simone, 2011).

Há uma segunda linha de pensamento sobre cidades do Sul - mais radical na minha opinião e que tem conquistado espaço nas literaturas da "teoria do Sul". Por exemplo, a noção proposta por Comaroff e Comaroff (2011) de que é 
a Europa e os Estados Unidos que têm a tendência de evoluir de acordo com os processos observados na África, e não o contrário, como é tipicamente presumido. O mesmo também pode ser verdade para cidades... (Comaroff \& Comaroff, 2011).

Em alguns pontos, [as cidades do Sul] estão... até mesmo prefigurando o que pode acontecer (para melhor ou para pior) em cidades ocidentais (Choplin, 2012).

Uma variante desta proposição que flui da "teoria do Sul", em geral, é que "as cidades do Sul" apresentam um espaço de experimentação que prefigura o futuro próximo do Ocidente (ou Norte). Em outras palavras, para Obarrio (2012b), enquanto as colônias podem ter sido o primeiro laboratório da modernidade, acredita-se que há algo de novo nas maneiras culturais, econômicas e políticas em que o Sul prevê os contornos do futuro euro-americano. Observei que os conhecimentos fundamentados sobre o que ocorre nas periferias de São Paulo podem ser úteis para contar histórias de vida e pensar sobre a prática urbana nos subúrbios ou na grande couronne de Paris. O que a cidade é para residentes urbanos comuns pode tornar-se realidade através de relatos da vida social nas cidades do Sul apresentados por muitos destes autores. Desta forma, esta crítica necessariamente eclética mostra algumas das razões para o entusiasmo que as noções do "urbanismo do Sul" têm gerado ao longo da última década.

\section{Ceticismo e a "nova" teoria das cidades do Sul}

Parece-me que muito do que está sendo escrito atualmente "sobre o Sul", propõe uma análise das cidades do Sul a partir de conceitos e de ferramentas que emanam de estudos urbanos de muito tempo atrás e de outros lugares. Nas páginas das coletâneas de, por exemplo, Edensor e Jayne (2012), ou até mesmo de Roy e Ong (2011), está clara a busca, um tanto improdutiva, pela emergência de um novo marco conceitual substantivamente diferente para lidar com as cidades contemporâneas do Sul.

A análise da especulação e da mudança em Bangalore de Goldman (2011), por exemplo, pode muito bem apresentar terminologias familiares aos autores pesquisados acima, mas as linhas principais de pesquisa e argumento parecem vir de outro lugar: isto é, do cânone Norte/Ocidente. O mesmo parece ser verdade em muito daquilo que os autores relatam nas páginas da coletânea de Mayaram (2012) The other global city, que é um conjunto de textos que permanecem totalmente dependentes dos "pontos de referência do Norte". Pode bem ser que a relativa negligência em relação a cidades como Istambul e Tóquio, nas bibliografias ocidentais, seja um sinal de seu esgotamento, mas não significa que algo substancialmente diferente 
seja teoricamente apresentado. Por si só, correções empíricas para esta falta de atenção não produzem a mudança necessária para um novo pensar. Apesar das intenções, este livro não alcançou seus objetivos de ir além das leituras corriqueiras das cidades, tanto imperialistas como nacionalistas.

Ao seguir Chakrabarty (2000), Robinson (2003) reivindica o reconhecimento da condição presente na produção da teoria urbana, um sentimento ecoado por Edensor e Jayne (2012: 6). Pode-se aqui constatar alguma humildade, entretanto a mesma luz pode iluminar outras direções. Todos estamos inseridos em um cânone limitado, bastante apartado de onde estamos fisicamente situados: aqui linguagem é um limite profundo.

Choplin (2012) aponta para os perigos que uma sociologia do conhecimento corre nessa predominância anglófona no mundo das ideias e clama para que a produção francófona seja tomada em consideração (poderíamos adicionar também o trabaIho hispânico, lusófono, germanófono, sinófono, entre outros). Choplin segue advertindo sobre a idealização da produção científica anglófona. Há geralmente um grande potencial para as autocitações que demarcaram certos grupos de acadêmicos. Nesse contexto, algumas das verdadeiras dificuldades das "perspectivas urbanas do Sul" podem se tornar mais aparentes aos observadores.

O consenso reivindicado por Parnell (2012) - de que a teoria do Sul é o caminho que devemos seguir para pensar "as cidades" - pode ser suficiente para alguns, mas, para outros, é demasiadamente amplo e vago no terreno dos estudos urbanos.

Ademais, a argumentação de Roy (2009) de que as

teorizações dominantes das regiões-cidades globais estão arraigadas na experiência euro-americana e, por isso, são incapazes de analisar formas múltiplas de modernidades metropolitanas (Roy, 2009, destaque meu)

requer um certo cuidado, pois permanecem confusas quais as relações entre sociedade e cidade no hiperdiverso "Sul", esquivando-se das ideias formadas no "Ocidente" ou no "Norte".

A ideia sobre o que está acontecendo nas cidades do Sul deve agora informar o que se entende por cidades do "Norte" e parece atraente, mas são conceitos empiricamente mal fundamentados. O risco da adoção integral de tais caracterizações pode ser "um conjunto maior de declarações que tendem a obscurecer mesmo quando afirmam esclarecer" (Aravamudan, 2012). Gravar, comparar e justapor as 
experiências urbanas das cidades por todo o mundo, como Rodgers (2012: 134) sugere, significa que "identificar quaisquer dinâmicas universais na urbanização global argumentativamente depende [...] do entendimento de [...] circunstâncias específicas". Assim, parece-me inadequado propor que as "cidades do Sul" forneçam novos modelos para cidades, em geral.

Em termos analíticos, enquanto Chicago forneceu tantos modelos com tamanho sucesso por muito tempo, outras escolas têm contestado sua centralidade nas décadas mais recentes (a exemplo da "Escola de Los Angeles", ou de suas congêneres nos Estados Unidos, incluindo Nova York, Atlanta e Miami). Importantes para a ideia destes últimos modelos de cidade, sua sociedade, sua geografia entre outras características, são elementos como o cosmopolitismo continuado, a diversidade de forma e o policentrismo, ambos geográficos e de outras formas; e talvez, no caso de Miami (mas de outros lugares também), algo especial sobre as cidades "importantes" e seus outros lugares. Certamente, tão logo li o emprego do termo "euro-américa", fiquei desconfiado sobre o fracasso de abordar com a grande diversidade e sutileza a exigência de alguns que desejam que levemos a sério o "urbanismo do Sul" e seu potencial teórico.

Há lacunas importantes nas afirmações recentes sobre as cidades do Sul, talvez refletindo um esquecimento das múltiplas formas da vida social discutidas por muitos autores em cidades americanas - observando, por exemplo, que nem tudo é "formal", que a governança não é completa, como muito bem mostra Devlin (2011) para um exemplo contemporâneo convincente. Além disso, as chamadas recentes para a realização de pesquisas comparativas por todo o globo têm precedentes históricos. Exemplo pode ser encontrados em Castells (1983), Marcuse et alii (2011) e no projeto de Burgel intitulado Villes en parallele (Burgel \& Conrado Sondereguer, 2010).

Novas representações retóricas podem ser surpreendentemente poderosas, ao menos para alguns, mesmo quando não acrescentam muito, no sentido de proporem novas concepções. Pieterse (2012) insinua isso em sua crítica à celebração da provisionalidade presente nesta literatura. Por isso, a pergunta ainda permanece: o que os teóricos das cidades do Sul têm realizado conscientemente para ir além do é, do que foi feito no Norte? Há algum motivo para não abordar conceitos do Norte nas cidades do Sul?

Se apelos em prol da teoria das cidades do Sul revelam lacunas ao considerarem o que "veio do Norte" - como Aravamudan (2012) sugere -, alguma literatura recente preconiza que o que vemos "[é] muito menos "do Sul" e muito mais "sobre o Sul". Eagleton (1999), ao aplaudir Spivak por suas contribuições, notou que muito do 
pós-colonialismo é um tipo de versão "exportada" dos próprios problemas étnicos dos Estados Unidos.

Um problema posterior diz respeito ao fato de relatos pós-coloniais de poder abandonarem direitos, liberdades e conquistas arduamente conquistados em 1886, 1835, 1789 no "Norte" (Chatterjee, 1993; Chakrabarty, 2000; Chibber, 2013, especialmente nos capítulos 7 e 8). Purcell (2007) parece razoavelmente criterioso ao escrever:

É especialmente importante que os democratas em economias avançadas percebam que... novos movimentos democráticos mais empolgantes devem surgir na América do Sul e na África, assim como eles surgiram em Nova York e em Bruxelas (Purcell, 2007: 204).

Contudo, o inverso não deixa de ser igualmente verdadeiro.

Quando uma ordem abrangente, democrática e consensual finalmente emergiu de maneira lenta [no Ocidente], no século XIX e início do século XX, ela não foi um presente concedido pelos capitalistas. Na verdade, foi um produto de longas lutas conjuntas realizada por trabalhadores, fazendeiros e camponeses (Chibber \& Birch, 2013).

Nesse sentido, um pouco mais de cautela é necessário antes de comemorar as "sociedades de resistência" que contribuem ao urbanismo autóctone, mas que podem também e simultaneamente serem "integradas em circulações de capitais globais [que] não podem ser pensadas como tendo origem de baixo para cima ou de cima para baixo", conforme Roy (2011) observa.

Uma tendência que eu diferencio na autodenominada obra do "Sul" é a ênfase superlativa outorgada às disparidades de renda e, por consequência, aos temas de identidade e cidadania das cidades do Sul quando se as compara com as cidades ocidentais/do Norte.

Condições diferenciadas nas próprias cidades ocidentais/do Norte são ignoradas: a banlieue (o subúrbio), por exemplo, torna-se homogêneo em muitas considerações - pela cor negra, a incidência de desemprego dos jovens -, como citado em Simone (2011). Contudo, o que mais aprendi em alguns meses vividos na banlieue parisiense foi a multiplicidade e a diversidade de suas condições: de forma alguma foi percebida como simplesmente parte das "malogradas terras da República" (Dikeç, 2007). 
Afirmações mais explícitas sobre o "novo" emergem em outra recente coletânea (Samara et alii, 2013a). Aqui, três aspectos determinantes sobre a cidade são investigados:

1. a polarização social e a divisão especial;

2. a transformação de certos bairros em paisagens cosmopolitas; e

3. as políticas confusas que surgem das... mudanças que as cidades estão padecendo.

Para mim, essas características parecem ser observações comuns frequentemente feitas muito mais sutilmente em literaturas consagradas a Nova York, Londres, Paris, Berlim e Moscou, entre outras tantas, e, por isso, podem constituir-se em "um identificável... urbanismo transnacional, distinto do Sul Global” (Samara et alii, 2013b: 2).

Como previamente observei,

muitas das produções escritas atualmente justapõem pontos de vista acadêmicos abrangentes sobre o que está acontecendo nas cidades com jornalismo colorido sobre um evento local. O pressuposto do autor frequentemente parece ser que as duas coisas estão relacionadas. Mas, boa parte do tempo, não estão (Mabin, 2011: 1972).

No processo, o que é especial sobre a teoria subalterna e pós-colonial "do Sul" parece estar perdido: a experiência e a persistência das culturas colonizadoras na vida dos cidadãos. Talvez isso não seja surpreendente, porque, em boa parte dos casos de recentes coletâneas de trabalhos sobre e nas "cidades do Sul", os autores moram, trabalham e observam o objeto de sua pesquisa, na maior parte do tempo, a partir das cidades do Norte do mundo, levando preocupações exógenas para um terreno inadequado.

A teoria urbana do Sul parece ter dificuldade em transferir as contribuições da academia do Sul para a cidade do Norte, além da abrangente generalização frequentemente realizada sobre populações imigrantes recentes. Consequentemente, ela quase não fornece uma base consistente para se pensar o formato coletivo do futuro das cidades. O trabalho contínuo sobre política, economia, história e vida cotidiana das cidades do Sul, em toda a sua gloriosa diversidade, oferece um vislumbre de algo emocionante e ocasionalmente distinto. É por esta razão que celebro as contribuições de muitos acadêmicos neste campo, no início deste texto. Contudo, o que temos disponível, no presente, ainda não nos leva muito longe, até essa Terra Prometida do urbanismo do Sul. 


\section{E a ação!}

\section{baseada na teoria do Sul?}

Parte do projeto da "teoria da cidade do Sul" é um programa de ação, construído a partir de uma longa tradição de acadêmicos engajados, aos quais sou muito solidário (Oldfield et alii, 2004; Yiftachel, 2006; Watson, 2009).

A emergência de novos estados de bem-estar social pode ilustrar aquilo que Comaroff and Comaroff apontam como inovações que surgem do Sul. Pelos problemas sociais que se busca responder - altos índices de desemprego persistente, informalização crescente, coexistência de pobreza em massa com regimes democráticos -, essas questões já não aparentam ser específicas de uma forma ou experiência que possa ser delimitada pelo "Terceiro Mundo". Ao contrário, elas aparentam ser altamente relevantes para descrever também o que se passa em lugares como os Estado Unidos (Ferguson, 2012).

A linha de pensamento de Ferguson certamente apresenta pontos comuns com a de Robinson e Parnell (2011), que sinaliza os limites para se assumir a intencionalidade neoliberal global na gestão urbana (ver Pieterse, 2012). Entretanto, ela é parcialmente questionada por outros, como Caldeira (2011), sobre São Paulo, que escreve muito sobre a deterioração das condições da (maioria?) dos pobres, ou dos excluídos, ou simplesmente dos jovens, em sua cidade natal (Caldeira, 2000).

A avaliação de Ferguson que sugere uma elevação dos padrões de vida para a maioria é contestável. Alguns urbanistas brasileiros mantêm seus pontos de vista sobre as cidades do país continuarem fundamentalmente em crise e que as coisas estão se tornando cada vez mais problemática para muitos. Contudo, eles também apresentam casos de complexidades que estão aumentando rapidamente. Para Caldeira, "mundos separados" na cidade (Caldeira, 2011) representam profundas fraturas, e as cidades brasileiras viveram o resultado disto em meados de 2013.

Alguns autores e ativistas que forneceram análises de base nas décadas de 1980 e 1990, e desempenharam um papel central na reforma urbana por várias décadas, também veem elementos de avanço (Maricato, 2001; 2009). Essas melhores circunstâncias da cidade aconteceram por muitas razões e eu as examinei em outros trabalhos (Mabin, 2012). Se a autorrepresentação de São Paulo como cidade global for um "mito", de acordo com Whittaker Ferreira (2007), ela é, contudo, uma cidade promissora, em crescimento, e cada vez mais bem administrada, na qual alguns projetos principais na escala metropolitana fizeram a diferença na vida cotidiana, em um cenário de "novo" milagre econômico brasileiro. 


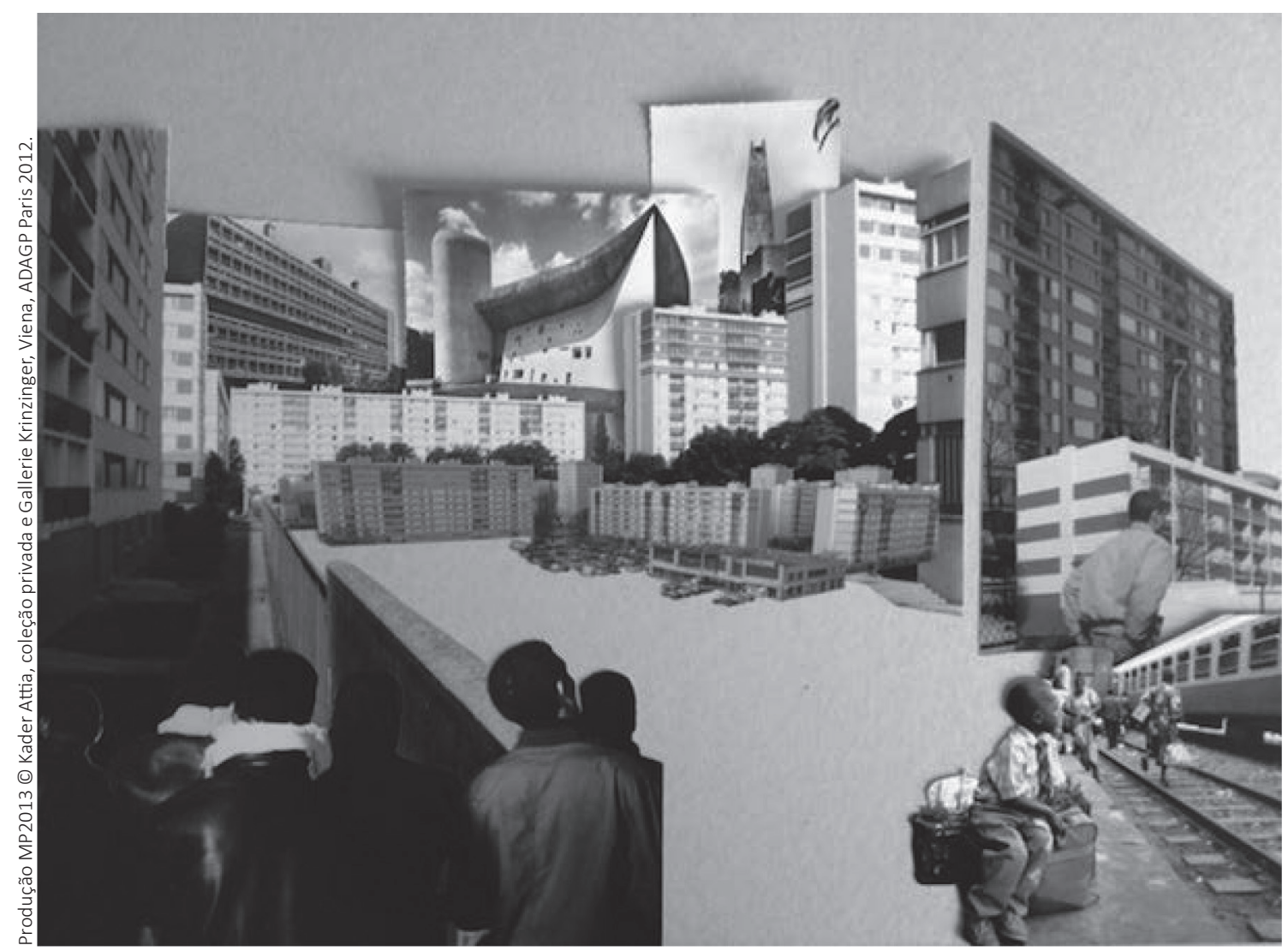

Como todos sabem, as formas pelas quais produzimos conhecimento sobre a cidade, nos dias de hoje, emerge tanto do reconhecimento das fragilidades como dos sucessos das ações coletivas, sejam elas de base ou resultantes da própria ação do Estado.

Nesse sentido, uma última arena de debate sobre a teoria do Sul está começando a se desenvolver. Ela pode ser vista através de algumas experiências recentes na África do Sul. Como exemplo, pode-se examinar a tentativa de Robinson e Parnell (2011) em unir as noções de observações cotidianas do planejamento com a experiência da "estratégia de desenvolvimento da cidade", utilizada primeiramente na África do Sul, mas também em outras cidades do Sul (ver, também, Robinson, 2011a; 2011b). Os autores afirmam que se pode, por meio dessas noções, chegar a algo além do neoliberalismo global, ao se levar a sério algumas das estratégias de desenvolvimento que as cidades do Sul encontraram. Uma dificuldade-chave na construção (do Norte) das perspectivas do Sul parece ser a imposição das recentes tendências históricas em "histórias do Sul": 
A virada em torno da privatização, desregulamentação e liberação... avalia proeminentemente a nova pesquisa e as obras sobre o urbanismo transacional. Ao responder ao desafio neoliberal, as autoridades municipais do Sul Global estabeleceram novas regiões reguladoras que removeram obstáculos institucionais, barreiras legais e barreiras administrativas a fim de pavimentar o caminho para fazer com que o Mercado funcione eficientemente através do enxugamento, da terceirização e do ajuste ao tamanho apropriado dos serviços municipais (Murray, 2013: 295).

O problema é que muitas cidades do Sul não se valeram dos elementos relatados neste tipo de descrição. Ao contrário, há casos em que municípios estão procurando mudar precisamente na direção oposta. Parece que alguns profissionais leem autores tais como Roy como sendo contra o planejamento, contra projetos e contra o urbanismo (Fiori \& Brandão, 2010: 189-190).

Contudo, a questão central da falta de conhecimento e (talvez) o problema do conceito de cidades do Sul, conduza a uma necessidade imperiosa de profunda e minuciosa pesquisa sobre o que está acontecendo. A elisão entre tentativas superficiais neste tipo de pesquisa e do mundo sobre "o que deve ser feito" permanece uma falha fundamental dos textos sobre as cidades do Sul: e talvez, também do Norte. Por fim, é necessário, em alguns casos, enxergar o que está emergindo como tentativa de unir as cidades de todo o mundo.

\section{Conclusão:}

\section{fundamentação de ideias nas cidades do Norte e do Sul}

O ponto principal para as abordagens mais profundas, animadoras e menos transversais poderá ser encontrado em métodos comparativos muito mais cuidadosamente elaborados. Pontos de comparação específicos parecem necessários (Le Gales \& Vitale, 2013), "abrindo novos canais de pesquisa urbana e de formação em políticas públicas em um universo mais amplo das cidades" (Harris, 2012). Isso significa abrir novos canais com o Leste, o Oeste, o Norte, assim como o Sul.

Meu trabalho atual, por exemplo, está centrado em minha própria cidade natal e onde exerço minha vida acadêmica - Johanesburgo - e em duas cidades em que passei bastante tempo realizando pesquisa: São Paulo e Paris. Não busco universalidades em meu trabalho, mas afirmaria que mais pontos gerais surgem enquanto exploro a governança, as políticas, o planejamento, a mudança em larga escala, megaprojetos, mobilidade e elementos da vida cotidiana nas regiões dessas cidades (Mabin, 2012). 
Estou envolvido em uma pesquisa para expressar apenas algumas coisas que me parecem como características vitais da questão urbana nos dias de hoje. Certamente não tenho a pretensão de esgotar o assunto, muito menos cumprir "a promessa da cidade" (Tajbaksh, 2001). Meu método inclui "a comparação [que] pode ser concebida como uma estratégia de aprendizagem indireta e incerta", isso talvez porque eu tenha trabalhado razoavelmente e de maneira similar nestes três lugares, em diferentes continentes, com a tendência de duvidar que o que torna as coisas mais claras é sua "transformação em uma teoria urbana com orientação predominantemente europeia e americana" (McFarlane, 2008).

Talvez haja pouco futuro para a teoria urbana em um mundo onde a "urbanização foi generalizada" (Brenner, 2013: 93). Contudo, mesmo se o Planeta fosse totalmente "urbano", ao teorizar a cidade ainda teríamos de lidar com a diferença - em outras palavras, a diversidade do urbano e a diferença que essa diversidade acarreta para a sociedade. A noção de que o mundo é "todo urbano" nega a experiência de lugares que não são como Manhattan - e de muitos que moram e trabalham lá, cujas unidades sociais se estendem por espaços surpreendentes. Steinberg (2011) apresenta uma ilustração maravilhosa sobre o tema. Por isso, a tese de Brenner (2013: 101) de que "o conceito de urbanização requer reinvenção sistemática" convida para a tradução de uma reinvenção contínua e diversa, assim como a identificação específica do transitório ou do perene.

O trabalho simultâneo nas três cidades da África, Europa e América do Sul impõe-me a exigência de dar continuidade a este exame. Os acadêmicos que estão envolvidos em estudos sobre a cidade continuarão a entrar em avenidas menos frutíferas: uma simples "tomada do Sul" não resolverá os problemas arrogantes e puramente do Norte. Ninguém, nem um único grupo, terá total sucesso em colocar em conexão a extensão do urbanismo contemporâneo. É essencial atravessar as barreiras linguísticas, as disciplinas, os conceitos e todos os tipos de outros limites. Contudo, ele ainda permanecerá inevitavelmente incompleto. O prazer estará então no mútuo envolvimento.

Abstract: While sympathetic to a project of global southern urban theory and its intent, this article is sceptical of the utility of "urban theory from the south". What we need, or lack, is not solely to be addressed by development of a theory from and of the south, for the world is not so simply divided. The article rejects the notion, for instance, that "northern" urban theories are not useful in the south. It suggests instead that theories travel, and in doing so, are richly populated in place, region, networks, and in conversation. Working between Paris, Johannesburg and São Paulo, the article calls for thinking in relation, in pathways across conventional terrain of north and south.

keywords: Southern theory, cities of south, connection, relation. 


\section{Referências}

AHMAD, A. In theory. Nations, classes, literatures. London: Verso, 2008.

AMIN, A.; THRIFT, N. Reimagining the urban. Cambridge: Polity Press, 2002.

APPADURAI, A. Modernity at large. Cultural dimensions of globalization. Minnesota: University of Minnesota Press, 1996.

- Spectral housing and urban cleansing. Notes on millennial Mumbai. Public Culture, v. 12, n. 3, p. 627-651, 2000.

ARAVAMUDAN, S. Surpassing the North: Can the antipodean avantgarde trump postcolonial belatedness? In: OBARRIO, J. (Ed.). A forum on theory from the South: How Euro-America is evolving toward Africa, por Jean e John Comaroff, 2012. Disponível em: <http://www.culanth.org/?q=node/502 2012-02-24 12:26>.

BHABHA, H. The location of culture. New York: Routledge, 1994.

BRENNER, N. Theses on urbanization. Public Culture, v. 25, n. 1, p. 85-114, 2013.

BURGEL, G.; CONRADO SONDEREGUER, P. (Eds.). Paris, Buenos Aires aller-retour. Villes en Parallele, n. 42-43, 2010.

BURKE, T. Eyes wide shut: africanists and the moral problematics of postcolonial societies. African Studies, Quarterly, v. 7, n. 2-3, 2003. Disponível em: <http://www. africa.ufl.edu/asq/v7/v7i2a12.htm>. Acessado em: 13 Maio 2013.

CALDEIRA. Worlds set apart. In: BURDETT, R.; SUDJIC, D. (Eds.). Living in the endless city. Londres: Phaidon, 2011.

- City of walls. Crime, segregation and citizenship in São Paulo. Berkeley: University of California Press, 2000.

CASTELLS, M. The city and the grassroots: a cross-cultural theory of urban social movements. Berkeley (CA): University of California Press, 1983.

—. The urban question: a marxist approach. Cambridge (MA): MIT Press, 1977.

CESARINO, L. Brazilian postcoloniality and South-South cooperation: a view from anthropology. Portuguese Cultural Studies, n. 4, p. 85-113, 2012.

CHAKRABARTY, D. Provincializing Europe. Postcolonial thought and historical difference. Princeton: Princeton University Press, 2000.

CHATTERJEE, P. The nation and its fragments: colonial and postcolonial histories. Princeton: Princeton University Press, 1993. 
CHIBBER, V. Postcolonial theory and the specter of capital. London: Verso, 2013.

CHIBBER, V.; BIRCH, J. Interview: how does the subaltern speak? Postcolonial theory discounts the enduring value of enlightenment universalism at its own peril, 2013. Disponível em: <http://www.europe-solidaire.org/spip.php?article28483>. Acessado em: 01 Abr. 2013.

CHOPLIN, A. De-Westernising urban theory. Metropolitics, 5 Dez. 2012. Disponível em: <http://www.metropolitiques.eu/De-Westernising-Urban-Theory.html>.

COMAROFF, J.; COMAROFF, J. Theory from the South: a rejoinder. In: OBARRIO, J. (Ed.). A forum on theory from the South: How Euro-America is evolving toward Africa, por Jean e John Comaroff, 2012. Disponível em: <http://www.culanth.org/?$q=$ node/502 2012-02-24 12:26>.

- Theory from the South: or, how Euro-America is evolving toward Africa. Boulder: Paradigm Publishers, 2011.

CONNELL, R. Southern theory: social science and the global dynamics of knowledge. Sydney; Cambridge: Allen \& Unwin Australia; Polity Press, 2007.

DELEUZE, R. G. E GUATTARI, F. What is philosophy? New York: Columbia University Press, 1994.

DEVLIN, R. T. "An area that governs itself": Informality, uncertainty and the management of street vending in New York City. Planning Theory, v. 10, p. 53-65, 2011.

DIKEÇ, M. Badlands of the Republic: space, politics and urban policy. Oxford: Blackwell, 2007.

DUMINY J. Raewyn Connell and directions for urban agency, 2011. Disponível em: $<$ http://southernplanningtheory.blogspot.fr/2011/07/raewyn-connell-anddirections-for-urban.html>.

EAGLETON, T. In the Gaudy supermarket - A Critique of post-colonial reason: toward a history of the vanishing present by Gayatri Chakravorty Spivak. London Review of Books, v. 21, n. 10, p. 3-6, 1999.

EDENSOR, T.; JAYNE, M. (Eds.). Urban theory beyond the West. A world of cities. London; New York: Routledge, 2012.

FIORI, J.; BRANDÃO, Z. Spatial strategies and urban social policy: urbanism and poverty reduction in the favelas of Rio de Janeiro. In: HERNANDEZ, F.; KELLETT, P.; ALLEN, L. K. (Eds.). Rethinking the informal city: critical perspectives from Latin America, p. 181-206, Oxford: Berghahn, 2010. 
FERGUSON, J. Theory from the Comaroffs, or how to know the world up, down, backwards and forwards. In: OBARRIO, J. (Ed.). A forum on theory from the South: How Euro-America is evolving toward Africa, por Jean e John Comaroff, 2012. Disponível em: <http://www.culanth.org/?q=node/502 2012-02-24 12:26>.

GOLDMAN, M. Speculating on the next world city. In: ROY, A.; ONG, A. (Eds.). Worlding cities: asian experiments and the art of being global, p. 229-258 Hoboken: Wiley-Blackwell, 2011.

GROVOGUI, S. A revolution nonetheless: the global South in international relations. The Global South 5.1, Edição especial: The Global South and World Dis/Order, p. 175-190, 2011.

GUÉNIF-SOUILAMAS, N. Is fanon finished?/Fanon. Et après?. em Obarrio (2012a). In: OBARRIO, J. (Ed.). A forum on theory from the South: How Euro-America is evolving toward Africa, por Jean e John Comaroff, 2012. Disponível em: <http://www. culanth.org/?q=node/502 2012-02-24 12:26>.

HARRIS, A. The metonymic urbanism of twenty-first-century Mumbai. Urban Studies, v. 49, n. 13, p. 2955-2973, 2012.

HARVEY, D. The right to the city. New Left Review, n. 53, p. 23-40, Sep-Oct, 2008.

- The condition of postmodernity. An enquiry into the origins of cultural change, London: Wiley-Blackwell, 1991.

HENRIKSEN, K.; EJDESGAARD JEPPESEN, A-M. Studies of postcolonialism and the Latin American tradition: national identities and Indigenous struggles. Copenhagen: Museum Tusculanum Press; University of Copenhagen, 2007.

JACOBS, J. Edge of empire: postcolonialism and the city. London: Routledge, 1996.

JAMESON, F. Postmodernism, or the cultural logic of late capitalism. Durham (NC): Duke University Press, 1990.

JÁUREGUI, J. Urban and social articulation: megacities, exclusion and urbanity. In: HERNANDEZ, F.; KELLETT, P.; ALLEN, L. K. (Eds.). Rethinking the informal city: critical perspectives from Latin America, p. 207-224, Oxford: Berghahn, 2010.

KÜBLER, D. Introduction: metropolitanisation and metropolitan governance. European Political Science, n. 11, p. 402-408, 2012.

LATOUR, B. We have never been modern. Cambridge (MA): Harvard University Press, 1993.

LEFEBVRE, H. Writings on cities. Oxford: Blackwell, 1996. 
LEFÈVRE, C. The improbable metropolis: decentralization, local democracy and metropolitan areas in the Western world. Análise Social, Ano XLV, n. 197, p. 623-637, 2010.

LE GALES, P.; VITALE, T. Who is governed? What is governed and how? Comparing governance modes in large metropolis, versão preliminar apresentada no Governing Paris and Mexico, Première conférence Sciences Po/CEE, COLMEX, 27-28 Fev. 2013.

LEONTIDOU, L. Alternatives to modernism in (southern) urban theory: exploring in-between spaces. International Journal of Urban and Regional Research,v. 20, n. 2, p. 178-195, 1996.

MABIN, A. Spatial justice as viewed from Gauteng, South Africa: professionals, planning, possibilities. In: FOL, S.; LEHMAN-FRISCH, S.; MORANGE, M. (Eds.). Ségrégation et justice spatiale, p. 335-353. Paris: Presses Universitaires de Paris Ouest, 2013.

- Metropolitan democracy: themes and possibilities in São Paulo, Johannesburg and Paris. Governing the metropolis: powers and territories. New directions for research. Hôtel de Ville de Paris, 28-30 Nov. 2012. Disponível em: <http://governingthemetropolis.com/le-deroule/sessions-sessionsprogram/session-6-5-mabin/>.

- Review of Martin Murray taming the disorderly city. Urban Studies, v. 48, n. 9, p. 1971-1973, 2011.

. The urban world through a South African prism. In: BEAUREGARD, R.; BODY-GENDROT, S. (Eds.). The urban moment. Los Angeles: Sage Urban Affairs Annual Reviews, n. 49, p. 141-152, 1999.

MARCUSE, P. "Dual city": a muddy metaphor for a quartered city. International Journal of Urban and Regional Research, v. 13, n. 4, p. 697-708, 1989.

MARCUSE, P.; CONNOLLY, J.; NOVY, J.; OLIVIO, I.; POTTER, J. (Eds.). Searching for the just city. Londres; Nova York: Routledge, 2011.

MARICATO, E. Fighting for just cities in capitalism's periphery. In: MARCUSE, P.; CONNOLLY, J.; NOVY, J.; OLIVIO, I.; POTTER, J. (Eds.). Searching for the just city, p. 194-213. Londres; Nova York: Routledge, 2011. 2001. . Brasil, cidades: alternativas para a crise urbana. 3. ed. Petrópolis: Vozes,

MAYARAM, S. (Ed.). The other global city. Nova Delhi: Yoda Press, 2012. 
MBEMBE, A. Theory from the Antipodes. Notes on John and Jean Comaroff's TFS. In: OBARRIO, J. (Ed.). A forum on theory from the South: How Euro-America is evolving toward Africa, por Jean e John Comaroff, 2012. Disponível em: <http://www. culanth.org/?q=node/502 2012-02-24 12:26>.

- Sortir de la grande nuit, Paris: La Découverte, 2010.

_. On the postcolony. Berkeley: University of California Press, 2001.

MCCANN, E. Veritable inventions: cities, policies and assemblage. Area, v. 43, n. 2, p. 143-147, 2011.

MCFARLANE C. The comparative city: knowledge, learning, urbanism. International Journal of Urban and Regional Research, n. 34, p. 725-742, 2010.

- Urban shadows: materiality, the "southern city" and urban theory. Geography Compass,v. 2, n. 2, p. 340-358, 2008.

METH, P. Unsettling insurgency: reflections on women's insurgent practices in South Africa. Planning Theory and Practice, v. 11, n. 2, p. 241-263, 2010.

MORAÑA, M.; DUSSEL, E.; JAUREGUI, C. A. (Eds.). Coloniality at Large: Latin America and the postcolonial debate. "Latin America Otherwise book series". Durham (NC): Duke University Press, 2008.

MURRAY, M. Afterword: re-engaging with transnational urbanism. In: SAMARA, T.; HE, S.; CHEN, G. (Eds.). Locating right to the city in the Global South, p. 285-305. London: Routledge, 2013.

NEGRI, A. Time for revolution. London; New York: Continuum, 2005.

NUTTALL, S. Stylizing the self. In: NUTTALL, S.; MBEMBE, A. (Eds.). Johannesburg: the elusive metropolis, p. 91-118. Durham (NC): Duke University Press, 2008.

NUTTALL, S.; MBEMBE, A. (Eds.). Johannesburg: the elusive metropolis. Durham (NC): Duke University Press, 2008.

OBARRIO, J. (Ed.). A forum on theory from the South: How Euro-America is evolving toward Africa, por Jean e John Comaroff, 2012a. Disponível em: <http://www. culanth.org/?q=node/502 2012-02-24 12:26>.

- Theorizing the contemporary - theory from the south: Introduction. In: OBARRIO, J. (Ed.). A forum on theory from the South: How Euro-America is evolving toward Africa, por Jean e John Comaroff, 2012b. Disponível em: <http://www. culanth.org/?q=node/502 2012-02-24 12:26>. 
OLDFIELD, S.; PARNELL, S.; MABIN, A. Engagement and reconstruction in critical research: negotiating urban practice, policy and theory in South Africa. Journal of Social and Cultural Geography, v. 5, n. 2, p. 285-299, 2004.

PALING, W. Planning a future for Phnom Penh: mega projects, aid dependence and disjointed governance. Urban Studies, v. 49, n. 13, p. 2889-2912, 2012.

PARNELL, S. Learning about the world of cities: A geographer's reflections from the bottom of Africa. Artigo da palestra "A world of cities? Comparison across the disciplines". Manchester: University of Manchester, 17-18 Maio 2012. Disponível em: <http://stream.manchester.ac.uk/Play.aspx?Videold=11169>.

PIETERSE, E. High wire acts: knowledge imperatives of Southern urbanisms. Artigo da palestra em Joanesburgo sobre "Teoria e crítica". Salon, 2012. Disponível em: <http://jwtc.org.za/salon_volume_5/edgar_pieterse.htm>.

- Introduction: rogue urbanisms. Social Dynamics: A Journal of African studies, v. 37, n. 1, p. 1-4, 2011.

PIETERSE, E.; SIMONE, A. (Eds.). Rogue urbanism: emergent african cities. Johanesburgo: Jacana; African Centre for Cities, 2013.

PURCELL, M. City-regions, neoliberal globalization and democracy: a research agenda. International Journal of Urban and Regional Research, v. 31, n. 1, p. 197-206, 2007.

RAO, V. Slum as theory: the South/Asian city and globalization. International Journal of Urban and Regional Research, v. 30, n. 1, p. 225-232, 2006.

ROBINSON, J. Cities in a world of cities: the comparative gesture. International Journal of Urban and Regional Research, v. 35, n. 1, p. 1-23, 2011 a.

- The spaces of circulating knowledge: city strategies and global urban governmentality. In: McCANN, E.; WARD K. (Eds.). Mobile urbanism - cities and policymaking in the global age. Minnesota: Minnesota University Press. 2011b.

- Ordinary cities. Between modernity and development. London; New York: Routledge, 2006.

- Postcolonialising geography: tactics and pitfalls. Singapore Journal of Tropical Geography, v. 24, n. 3, p. 273-289, 2003.

ROBINSON, J.; PARNELL, S. Travelling theory: Embracing post-neoliberalism through southern cities. In: BRIDGE, G.; WATSON, S. (Eds.). The new blackwell companion to the city. Oxford: Blackwell Publishing, 2011. 
RODGERS, D. An illness called Managua: "extraordinary" urbanization and "mal-development" in Nicaragua. In: EDENSOR, T.; JAYNE, M. (Eds.). Urban theory beyond the West. A world of cities, p. 121-136. London; New York: Routledge, 2012.

ROY, A. Slumdog cities: rethinking subaltern urbanism. International Journal of Urban and Regional Research, v. 35, n. 2, p. 223-238, 2011.

- The 21st-century metropolis: new geographies of theory. Regional Studies, v. 43, n. 6, p. 819-830, 2009.

ROY, A.; ONG, A. (Eds.). Worlding cities: asian experiments and the art of being global. Hoboken: Wiley-Blackwell, 2011.

SALVATORE, R. The postcolonial in Latin America and the concept of coloniality: a historian's point of view. A Contra Corriente: A Journal on Social History and Literature in Latin America, v. 8, n. 1, p. 332-348, 2010. Disponível em: <www.ncsu.edu/ project/acontracorriente>.

SAMARA, T.; HE, S.; CHEN, G. (Eds.). Locating right to the city in the Global South. London: Routledge, 2013a.

SAMARA, T.; HE, S.; CHEN, G. Introduction: locating right to the city in the Global South. In: SAMARA, T.; HE, S.; CHEN, G. (Eds.). Locating right to the city in the Global South, p. 1-20. London: Routledge, 2013b.

SEEKINGS, J. Editorial, 2012. Disponível em: <http://www.ijurr.org/details/news/ 2339881/Virtual-Issue-on-Latin-American-Cities.html>.

SHEININ, D. Colonial and post-colonial Latin America", African Studies Quarterly 7 , n. 2-3, 2003. Disponível em: <http://web.africa.ufl.edu/asq/v7/v7i2a15htm>.

SIMONE, A. No longer the subaltern: refiguring cities in the global south. In: EDENSOR, T.; JAYNE, M. (Eds.). Urban theory beyond the West. A world of cities. London; New York: Routledge, 2012.

- City life from Jakarta to Dakar. Movements at the crossroads. London; New York: Routledge, 2010.

- The politics of the possible: making urban life in Phnom Penh. Singapore Journal of Tropical Geography, v. 29, p. 186-204, 2008.

- Deep into the night the city calls while the blacks come home to roost. Theory, Culture and Society, v. 24, p. 235-248, 2007.

SOKAL, A. Setting the record straight: a response to Gita Chadha. Economic and Political Weekly, 8 Abr. 2000. 
SPIVAK, G. Critique of postcolonial reason: toward a history of the vanishing present. Cambridge (MA): Harvard University Press, 1999.

STEDMANN JONES, G. Outcast London: a study of the relationships between classes. London: Penguin, 1976.

STEINBERG, J. Little Liberia: an african odyssey in New York City. Johanesburgo: Jonathan Ball, 2011.

TAJBAKSH, K. The promise of the city: space, identity and politics in contemporary global thought. Berkeley: University of California Press, 2001.

WA THIONG'O, N. Decolonising the mind: the politics of language in african literature. New Hampshire: Heinemann, 1986.

WATSON, V. Planning and the "stubborn realities" of global South-East cities: some emerging ideas. Planning Theory, v. 12, n. 1, p. 81-100, 2013.

- Seeing from the south: Refocusing urban planning on the globe's central urban issues. Urban Studies. v. 46, n. 11, p. 2259-2275, 2009.

WESTERN, J. Outcast Cape Town. London: Allen and Unwin, 1981.

WHITTAKER FERREIRA, J. S. O mito da cidade-global: o papel da ideologia na producão do espaço urbano. Petrópolis; São Paulo: Vozes; Editora Unesp, 2007.

YIFTACHEL, O. Re-engaging planning theory: Towards south-eastern perspectives. Planning Theory, v. 5, n. 3, p. 211-221, 2006. 